Epicurus on Sex, Marriage, and Children

Author(s): Tad Brennan

Source: Classical Philology, Vol. 91, No. 4 (Oct., 1996), pp. 346-352

Published by: University of Chicago Press

Stable URL: http://www.jstor.org/stable/270440

Accessed: 08-02-2016 21:23 UTC

\title{
REFERENCES
}

Linked references are available on JSTOR for this article:

http://www.jstor.org/stable/270440?seq=1\&cid=pdf-reference\#references_tab_contents

You may need to log in to JSTOR to access the linked references.

Your use of the JSTOR archive indicates your acceptance of the Terms \& Conditions of Use, available at http://www.jstor.org/page/ info/about/policies/terms.jsp

JSTOR is a not-for-profit service that helps scholars, researchers, and students discover, use, and build upon a wide range of content in a trusted digital archive. We use information technology and tools to increase productivity and facilitate new forms of scholarship. For more information about JSTOR, please contact support@jstor.org. 


\section{EPICURUS ON SEX, MARRIAGE, AND CHILDREN}

This paper reconsiders some familiar evidence, and introduces a new piece of evidence, in order to clarify Epicurus' attitudes towards two topics: sex on the one hand, and marriage and child-rearing on the other. Flouting propriety, I shall take up sex before marriage.

\section{EPICURUS ON SEX}

In an excellent article on the Epicurean telos, Jeffrey Purinton has argued that the scholarly community has misunderstood Epicurus' attitude toward sex, because it has mistranslated a key phrase. ${ }^{1}$

In D.L. 10.118 we read:

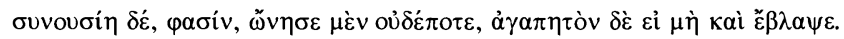

There is also a version of this text in the Vatican Sayings (VS 51), differing only by the omission of the kai. Translators have traditionally rendered the version with кai along the lines of:

They say that sex is never beneficial, and you are very lucky (or, "it is surprising," or

"it is marvellous") if it does not do harm as well.

So understood, commentators have taken Epicurus to be sounding a cautious note about sex. The desire for sex is natural, of course: its universality through all nations, tribes, and species attests to this. But it is not necessary; no pain ensues on its nonsatisfaction. And sexual activity frequently has harmful consequences-indeed, it is a surprising thing, you are very lucky, if it does not have such consequences. The satisfaction of sexual desire so frequently leads to pains of familiar and wellcatalogued kinds that the Epicurean calculator will seldom, perhaps never, judge it prudent to pursue sexual pleasures.

Purinton agrees in placing sexual desire among the natural non-necessaries. But he thinks that the last phrase has been misunderstood, in a way that makes Epicurus more hostile toward sex than he was. The proper translation on his view is as follows: ${ }^{2}$

[They] say that sex never benefits, but it is desirable, provided that it does not harm.

In a footnote, he points out that Cicero translated it in his way: ${ }^{3}$

genus hoc voluptatum optabile esse, si non obsit, prodesse numquam

So translated, the passage provides a more positive assessment of sex: sex is desirable. And the proviso concerning harm is not a gloomy prediction of probable dam-

1. "Epicurus on the Telos," Phronesis 38 (1993): 281-320. The merits of this article are many and varied; I cavil with one point, but find value in others.

2. Purinton, "Epicurus," 310, his italics. Although he translates the version from the Vatican Sayings that lacks the $\kappa \alpha i$, it would not be difficult for him to accommodate it. He would presumably then interpret the sentence along the lines of " . . provided it does not do harm, as well (sc. as satisfying the desire)."

3. Cic. Tusc. 5.94 . 
ages, but only the normal prudential tag that would be equally applicable to, for example, rich foods. Thus Purinton's translation transforms a generally pessimistic assessment of sex, and a general admonition to avoid it, into a more neutral or even positive assessment of its place in the pantheon of pleasures.

Is there a way of deciding between the translations? I believe that there is, but it is unfortunately tedious. The method is simply to inspect other passages of Greek

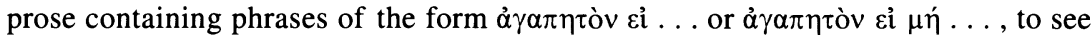
whether, in general, they tend to mean "and it is desirable, so long as etc.," as Purinton has it, or "and it is surprising if etc.," that is, "you should count yourself lucky if etc.," as the traditional view has it. I here present four passages that I believe are representative, the first two without $\mu$ ' and the second two with it.

(1) Of hunting-dogs, Arrian tells us, the female is generally faster than the male; but a good male is still a more valuable possession. ${ }^{4}$ It is better at hard work, it is uninterrupted by seasonal complications, and a good male is harder to find than a good female. Furthermore, the male dog, though slower, will keep its speed into its tenth year of age, but with the females:

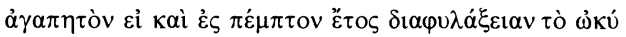

"Speed is a desirable thing, so long as they preserve it even into the fifth year"? No, that won't do. Surely what it means is, "with the females, it is surprising if they preserve their speed even into the fifth year." And, by implication, they rarely do.

(2) Galen comments on Hippocrates' saying that life is short and the art is long. ${ }^{5}$ None of us is capable of both creating the medical art and perfecting it in one lifetime:

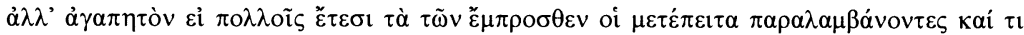

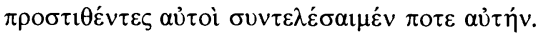

"But it is desirable, so long as those who come later, by taking over earlier discoveries and adding something of their own, should some day perfect it"? No, that won't do. Surely what it means is, "and in fact it will be a lucky thing if, through long eons of intergenerational collaboration, it should eventually be brought to perfection." So difficult is the art that, far from being within reach of one life span, it may not even be within the grasp of many.

(3) Aelius Aristides begs leave to speak with frankness: it will not please his hearers, but that is necessary to dispel the madness in their minds. ${ }^{6}$ And after all, doctors do not cure by doing everything for the sake of the patient's pleasure:

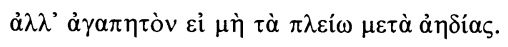

"But it is desirable, so long as they do the majority of things without unpleasantness"? No, that won't do. Surely what it means is, "and in fact it is surprising if most of their cures are not outright painful." And, by implication, most of their cures are painful.

5. Gal. in Hipp. Aph. (Kühn 17b.352).

6. Aristid. Peri homonoias tais polesin (Jebb, p. 533). 
(4) Become the paid companion of a wealthy patron, Lucian tells us, and immediately you will have lost the name of a free man. You may think your new position gives you power and prestige, but everyone else will deem you a slave: ${ }^{7}$

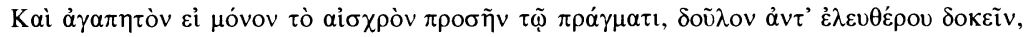

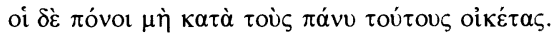

"And this is desirable, so long as it brings only shame, and not the pains of servitude"? No, that won't do. Surely what it means is, "and you will be lucky if it is only the name of a slave that you get, and not the life of a slave, too."

I have found many other passages in which this is clearly the sense. ${ }^{8}$ More importantly, as Bacon noted, I have found no passages with the contrary sense. But of course this does not mean that there are none to be found. The advocate of Purinton's position, it seems to me, must now shoulder the burden of proof, by bringing forward a passage in which the phrase is used in the way he suggests.

But one further point should be made, while these examples and the original Epicurean line are still before our eyes. In all of the instances that I have found, the neuter $\dot{\alpha} \gamma \alpha \pi \eta \tau$ tóv does not modify some particular word or phrase within the clause, but rather is an impersonal construction introducing the proposition that occurs after it. So, what is $\dot{\alpha} \gamma \alpha \pi \eta \tau$ óv is "that you should receive only shame, and not worse," or "that most cures are not positively painful," and so on. In the case of Epicurus, what is $\alpha \gamma \alpha \pi \eta \tau o ́ v$ is "that sex should not actually harm you." On Purinton's construal, it must modify ovvovoin, contrary to the syntax in all of the passages I have found.

Until very weighty evidence is brought forward to the contrary, it seems to me that we should feel confident that the traditional translation is the right one: sex is never beneficial, and you are lucky if it doesn't actually harm you-by implication, it usually does. The sentence does not say "sex is desirable"; the syntax does not connect those two words. As to Cicero's translation, I reluctantly conclude that he, like Purinton, simply got it wrong.

\section{Epicurus on Marriage ANd ChILd-REaring}

Did Epicurus advise the sage to marry and rear children, or did he deprecate the practice? Two connected problems obscure the Epicurean position. The first is that there is evidence to support both views. The second is that our best piece of evidence, D.L. 10.119, is flawed by textual corruption, in such a way that its meaning is ambiguous.

Several discussions have attempted to weigh all of the evidence and come up with a consistent position. ${ }^{9}$ I shall express my allegiance straight off: I think that Epicurus

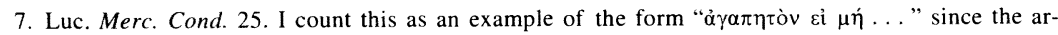
mature of the syntax is "you will be lucky if you don't receive pains."

8. See the list of citations in LSJ s.v. 2, and add: Alex. Aphr. Fat. 197.27; Dio Chrys. 17.6; Gal. de Crisibus K. 9.590; Ph. Leg. Alleg. 3.10; Plu. Praecepta 800c8; Xen. Cyr. 3.3.37. The idiom also appears with forms of $\alpha \gamma \alpha \pi \dot{\alpha} \omega$ itself (e.g., Lys. 12.11: "I asked him for funds, but he said I might count myself

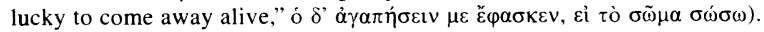

9. C. W. Chilton, "Did Epicurus Approve of Marriage? A Study of Diogenes Laertius X, 119," Phronesis 5 (1960): 71-74; A. Grilli, "Epicuro e il Matrimonio," Rivista Critica di Storia della Philosophia 26 (1970): 51-56; R. D. Brown, Lucretius on Love and Sex (Leiden, 1987), 119-20. M. Nussbaum has a brief and sensible endorsement of Chilton's position in The Therapy of Desire (Princeton, 1994): 152-53. 
advised against marriage and child-rearing for the most part, but permitted it in exceptional cases. This is not a new position. But previous discussions have not given sufficient weight to evidence and arguments that strengthen its credentials. Furthermore, the solution of a textual crux may give us a new piece of evidence, and at the same time remove a floating fragment from the Epicurean corpus (frag. 591 Us.), whose loss we shall not mourn.

There is extensive evidence, best collected by Chilton, that later readers took the Epicureans to be hostile to marriage and child-rearing. The evidence was sufficient to persuade Casaubon and Gassendi that the text of D.L. 10.119 should be emended, from reading:

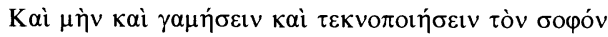

(i.e., "And indeed the wise man will both marry and rear children")

to reading:

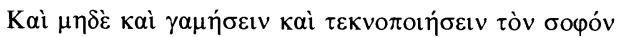

(Hicks: "Nor, again, will the wise man marry")

Chilton agreed that the original text could not be right, but favored emending to the syntactically more regular:

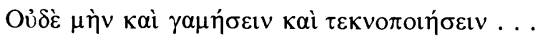

while retaining something like Hicks' translation.

I too am persuaded that the original must be emended, and am equally happy with either of the two emendations. I also agree with Chilton that strong confirmation is found in the next line of Diogenes' text:

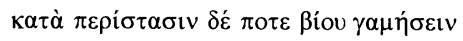

"But sometimes, in an exceptional circumstance in life, the wise man will marry"; this exception proves to us what the rule must have been. If there were not a general prohibition, there would be no need to make allowances for the odd case.

Not all critics have been convinced, however, and so it is time to bring forward new arguments. Curiously, I have not seen any modern ${ }^{10}$ critic make full use of Epicurus' own words, to show that he did sometimes advise certain Epicurean philosophers to marry and to rear children. These may be found in his will (D.L. 10.16-21), in which he orders his executors to care for various children ${ }^{11}$ until they come of age, as well as to arrange that the daughter of Metrodorus should be married to whomever Hermarchus should choose from among his students of philosophy, and to provide a dowry for her. ${ }^{12}$ These executors were Epicurean philosophers, and he

10. Charles Brittain reminds me that Cicero himself refers to the provisions in the will for the children of Metrodorus at De Finibus 2.98. The point made there is similar in its polemical intent, but directed more broadly at Epicurus' hedonism, and not specifically at the question of marriage and child-rearing.

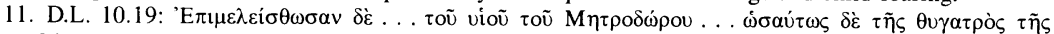

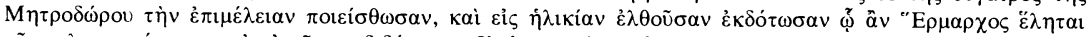

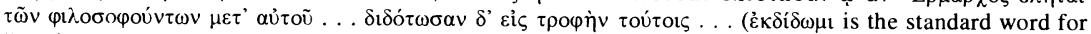
"to give away in marriage"). See also the further instructions in 10.21 .

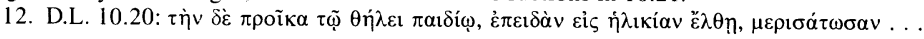


bids them see to the rearing of children. The student of Hermarchus will have been an Epicurean philosopher, and he bids him be married. Moreover, Metrodorus' daughter herself may have been an Epicurean philosopher.

These texts, then, show that Epicurus did permit and indeed encourage marriage and child-rearing-not as a rule, but for certain Epicureans, in certain circumstances. And they also indicate what sort of circumstances these were. I do not infer from this, however, that in his formal treatments of the topic he propounded lists of exceptional circumstances; indeed, he may never have mentioned the possibility of exceptions at all. The evidence of D.L. 10.119 might just as easily reflect later Epicurean attempts to make sense of the will itself, or comparable informal comments. In his treatises, he may have said things that seemed to express a universal prohibition; this would explain the impressions of later readers. But his will shows that he made allowances. I am inclined to think that it is philosophically consistent for him to do so. This is not one of those cases that Cicero likes to harp on, in which Epicurus managed to be a good man by being a bad Epicurean. ${ }^{13}$ But in either case,

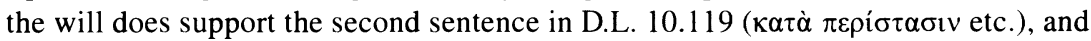
thus indirectly supports the emendation of the first sentence. By and large, Epicurus will advise Epicureans not to marry, but sometimes, in exceptional circumstances, he will advise certain of them to marry. ${ }^{14}$

What, though, shall we say about child-rearing? For that too is enjoined upon Epicureans in the will-again, not upon Epicureans in general, but at least upon certain Epicureans, namely the executors of the will. And yet D.L. 10.119 mentions no exception for rearing children. Instead, the text turns to two new maxims, unconnected to the earlier topics and to one another:

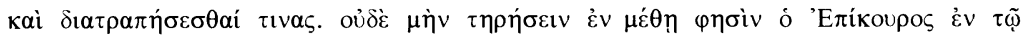

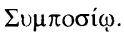

The second of these (frag. 63 Us.) makes little sense, and has been subjected to mass emendation. I follow Hermann and Hicks in preferring $\lambda \eta \rho \eta \dot{\sigma \varepsilon \iota v ; ~ " h e ~ w i l l ~ n o t ~ t a l k ~}$ nonsense when he is drinking." The first one (frag. 591 Us.) is equally curious, and no convincing translation has been proposed. The following are at least attested as attempts:

Hicks (followed by LSJ): Some too will turn aside from their purpose

Bailey: He will feel shame in the presence of some persons

Chilton: And some people he will avoid

There is disagreement over whether the future passive is being used with a transitive sense (Bailey and Chilton, retaining "the wise man" as the singular subject and taking $\tau \imath v \alpha \varsigma$ as the object) or with an intransitive sense (Hicks, in which case the plural $\tau ı v a \varsigma$ becomes subject). In either case it is taken to have an active or middle force. ${ }^{15}$

13. E.g., Fin. 2.80. The same assessment is given by Epictetus (Diatribes 3.7.17). While so-called Stoics talk a fine line but do not live up to it, the Epicureans are just as inconsistent in the opposite direction: they preach vicious doctrines but do noble things.

14. This will also confirm the testimony of Seneca (frag. 45 Haas), quoted by Chilton, that "Epicurus ... raro dicit sapienti ineunda coniugia. ..."

15. For lists of such deponents see, e.g., Smyth $\$ 806-13$. 
Unfortunately, none of these translations is even slightly satisfactory so far as doctrine goes, and none coheres with the context. Gassendi took the bull by the horns and changed $\delta 1 \alpha \tau \rho \alpha \pi \eta ́ \sigma \varepsilon \sigma \theta \alpha$ to $\tau \varepsilon \kappa v o \pi o t \eta ́ \sigma \varepsilon \imath v$, which Chilton calls "a very violent and unjustified change." Chilton is right that it is too violent to accept, but it is not wholly unjustified. For Gassendi was right to strive for a consensus integer cum priore parte $;{ }^{16}$ marriage and children have been yoked in the last sentence, and ought to be yoked here. Furthermore, they are habitually yoked together in other parallel discussions of the conduct of sages, Epicurean and otherwise. Let us look at a few.

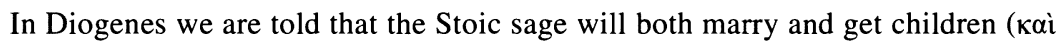

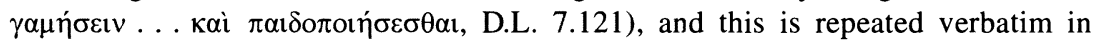

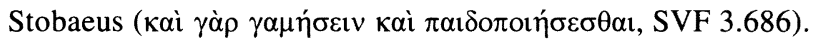

In Epictetus' discussions of the Cynic sage,${ }^{17}$ he attributes to them the view that in a proper Cynic polis, their sage will both marry and rear children, and that the children will be raised in proper Cynic fashion:

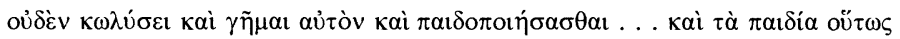
$\dot{\alpha} v \alpha \tau \rho \alpha \eta \dot{\sigma} \sigma \varepsilon \tau \alpha$.

It would be very nice, then, if we could retain this two-fold subject matter in our passage of Diogenes. And the last words quoted from Epictetus show us how to do it, so as to honor Gassendi's instinct, without offending Chilton's scruples. I propose that we emend as follows:

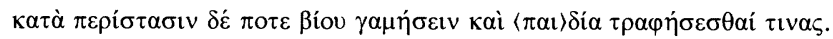

and translate:

But sometimes, in exceptional circumstances, certain sages will marry and rear children.

If this emendation is right, then the passage does not give a general license to Epicureans to beget new offspring (the $\tau \varepsilon \kappa v o \pi$ oın $\sigma \varepsilon ı v$ that Gassendi wanted). It only allows that, under certain circumstances, certain Epicureans will rear children, or see to their rearing. And this is exactly what Epicurus, in his will, had requested of his

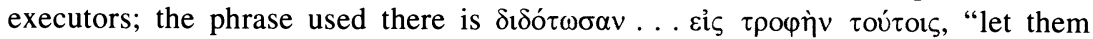
provide for the rearing of children." Thus, after stating the general prohibition on marriage and the getting of children, this passage attributes to Epicurus the minimal deviation that is consistent with the terms of his will. And this too suggests to me that it does not reflect explicit theoretical discussions in Epicurus' treatises, but rather later reflection on the will itself.

The paleographical demands of the emendation are slight. We suppose that $\pi \alpha \mathrm{t}$ dropped out after אaì, as the scribe's eye went from like to like, and we suppose that the $\varphi$ was at some time altered to a $\pi$, a very natural mistake given the extensive similarities between forms of $\tau \rho \varepsilon \dot{\pi} \pi \omega$ and $\tau \rho \varepsilon \dot{\varphi} \varphi$.

16. The quotation from Gassendi I take from Chilton's article.

17. Epictetus, Diatribes 3.22.68-69. 
The syntactical demand is slightly greater; we must take the future passive with the active or middle sense. While this usage is attested for many other verbs, $\tau \rho \varepsilon \tilde{\pi} \pi \omega$ among them as we saw above, I have been unable to find a parallel for it with $\tau \rho \varepsilon ́ \varphi \omega$. But I do not take this as a decisive strike against the emendation. Usage is fluid, and users follow the pattern of similar words in extending anomalies to new cases. The grammarian who feels that $\tau \rho \alpha \varphi \eta \dot{\sigma} \sigma \sigma \theta \alpha$ simply cannot take a middle

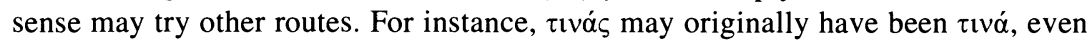
¿ıvós, ${ }^{18}$ in which cases the subject switches from the sage to the children, as it does in the passage of Epictetus above.

But that something like this is right seems to me overwhelmingly plausible. We should count it pure gain to rid ourselves of " $\delta \alpha \tau \rho \alpha \pi \eta \dot{\sigma} \sigma \varepsilon \sigma \theta \alpha$ " and the monstrous fragment (frag. 591 Us.) that it spawned. No longer must we suppose that the Epicurean sage "turns aside from his purpose," or "feels shame in the presence of others"-both of them incredible claims for any school to make about its sage. Instead, we have a perfectly natural continuation of the earlier discussion, which shows that the exceptional circumstances recognized in the case of marriage were also recognized in the case of child-rearing-exactly what Epicurus' own will tells us.

The evidence of the will thus coheres with our emendation of the text, and with

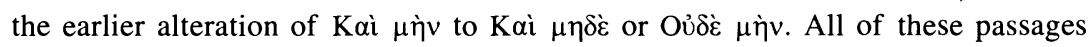
support the view that Epicurus was on record as advising, in general, against marriage and childrearing. But he also clearly thought that there were exceptions that justified both institutions, at least for certain Epicureans. And he was on record as saying this, too-perhaps in explicit comments in theoretical treatises, but at least through the contents of his will-so that later Epicureans had to incorporate this into their account of the master's views. I think that they were right to do so; nothing in the structure of Epicurean hedonism could justify the blanket prohibition. ${ }^{19}$

TAD BRENNAN

King's College, London

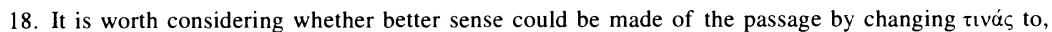

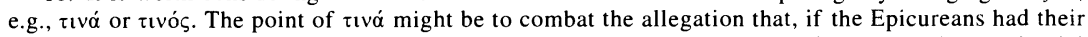

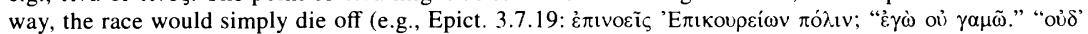

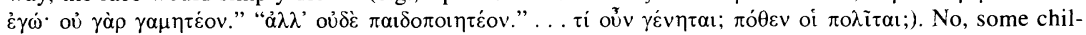
dren will still be raised, even in a city of Epicureans.

The point of $\tau \imath v o ́ \varsigma$ might be to describe a situation in which the Epicurean rears someone else's child, as happens in the will, or as Epictetus is said to have done. Simplicius records the story (Simp. in Epict. 116.48-52), otherwise unattested, that in his old age Epictetus married and reared a friend's child. This

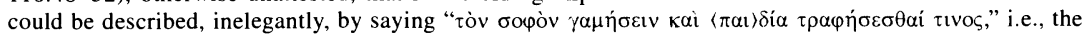
sage will marry and someone's children will be reared.

But neither of these alterations seems any improvement on $\tau \iota v \alpha \varsigma$. It seems more likely that the qualifier arose from the balancing act imposed on later students, by the conflict between Epicurus' generally negative comments about child-rearing, and the stipulations of his will.

19. Thanks are due to Jeffrey Purinton, who taught me much about Epicurus when we were students together, and to David Furley, who taught us both. It has been a pleasure to argue with Jeffrey over the years, and it is an even greater pleasure to contradict him: in this way, a student of David Furley's is guaranteed to be right (as long as the Epicureans are wrong about the excluded middle!). And, as always, my deepest thanks go to Liz Karns. 